\title{
Teaching with Scratch in Compulsory Secondary Education
}

http://dx.doi.org/10.3991/ijet.v11i02.5094

\author{
A.M. Ortiz-Colón ${ }^{1}$ and J.L. Maroto Romo ${ }^{2}$ \\ ${ }^{1}$ University of Jaén, Jaén, Spain \\ ${ }^{2}$ I.E.S. Oretania, Linares, Jaén. Spain
}

\begin{abstract}
The article analyzes the impact that the use of Scratch has in a group of students of Compulsory Secondary Education in the development of the teaching unit. For this we have studied the evolution of creative thought and analyzed the considerations made by the different actors involved, students and teachers. Qualitative and quantitative data are intended to complement the type of evidence and notes in research design followed. The tools used were the interview, field notes, diary of the researcher and the rubric adapted and created by Eduteka. The research results indicate that with the use of Scratch language students get better grades and are more motivated. As a conclusion, we can say that the application of the Scratch program improves school performance and student motivation significantly.
\end{abstract}

Index Terms - Didactic Unit, Compulsory Secondary Education, ICT, Rubric, Scratch.

\section{INTRODUCTION}

The paper presents the introduction of the Scratch language in secondary education in order to understand the impact of its implementation in the classroom teaching within the curriculum that is developed in Andalusia (Spain).

Scratch is a software application with a graphical interface that promotes cognitive development and motivation by carrying out activities in the classroom. Scratch is a project that has had great acceptance in schools since 2006 with the creation of the website of Scratch 1.0 project, being in 2013 when it reaches its greatest success with version 2.0. You can edit Scratch directly online and it is available in over forty languages.

Scratch allows users to create their own animations, games and interactive artistic productions, essential skills at present [1]. These features are in line with those of the web 2.0 collaborative spaces and synchronous tools, focused on student learning process, among others.

Scratch integrates constructivism and learning through action, ([2] [3]. Based on this theory, the "Life Long Kindergarten" (LLK), the Massachusetts Institute of Technology (MIT), opted for a tool that enables development by creating learning technology resources [4]. Creative thinking from the $\mathrm{LLK}_{\text {, }}$ is an iterative process that involves imagining what you want to do, creating what you have imagined, using the created material, sharing it and reflecting it on the outcome and potential improvements. Scratch is designed to promote this iteration [5], [6]. According to its developers, it is based on three fundamental principles [7] because the programming language is play- ful, meaningful and social [8]. These principles will be fully explained:

The programming language should be fun. The idea is that programming language provide the game and that can be tested, easily with different options.

The objective is for children to play with them from the beginning and try to build simple programs. The programming language should facilitate significant experience. Thus in designing Scratch, its creators have given priority to two design criteria: diversity and customization. Finally the use of the programming language should encourage social interaction. Scratch development is closely linked with the development of its website.

The basis for the success of Scratch is a community of people that can share, support, collaborate and build on the work of others. The goal is to eventually prove an experience of interactive and enriching learning for all [7 ]. We used the rubric designed by Eduteka Scratch to evaluate projects, in order to meet the criteria and progress of students in the design of their project with Scratch [9 ].

We have presented the project in a High School from Jaén (Spain) with first-year students of Compulsory Secondary Education to know the impact that the use of Scratch has in the subject of Natural Science. The project has been developed during twelve sessions over three weeks, to get the students used to Scratch language.

The use of this language has the advantage of requiring little knowledge of programming. It was planned to allow any child, teen or adult without programming experience to learn how to create their own animations and to obtain a final product quickly, using multimedia resources. It is a visual programming language in which we do not have to write code or long lines of programming.

The activity refers to the teaching unit "The temperature in the environment. The seasons", within the thematic cluster, "The Andalusian landscape". The goal of Scratch project seeks to answer the following questions of the teaching unit - what does the landscape around us look like?, what is the most usual one in Andalusia?, why?, how does the temperature influence the landscape?, do we know the average temperature of Andalusia or the average temperature in our village? See Figure 1(a) and Figure $1(b)$.

The project configuration is based on the organization of a series of graphics programming blocks. Finally following the logic of language Scratch, they are assembled to resolve the problem, mimicking what children do when playing with LEGO blocks, as shown in Figure 2. 
SHORT PAPER

TEACHING WiTH SCRATCH IN COMPULSORY SECONDARY EDUCATION

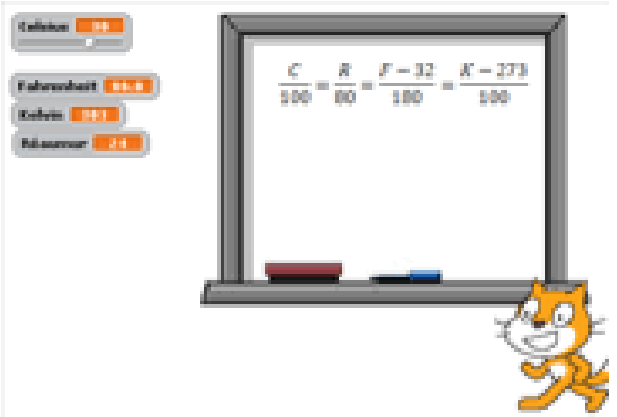

(a). Project example

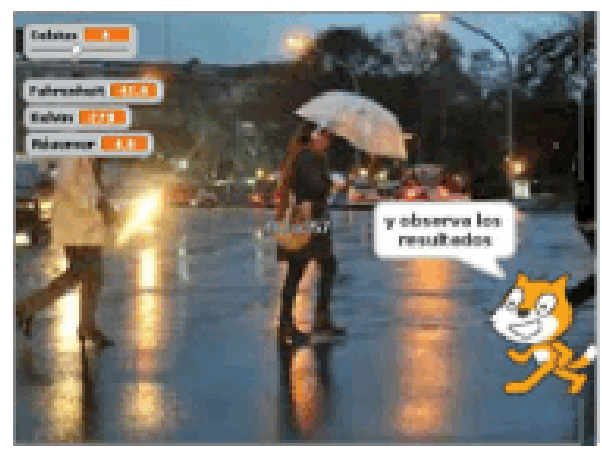

(b). Project Results

Figure 1.

The project is focused on the activity and student participation that encourages critical thinking, individual and cooperative work in the classroom. On the other hand, it encourages teamwork, favoring a multidisciplinary approach to the educational process with ICT as a tool facilitator for the development of the curriculum.

Project evaluation is done through the rubric as an assessment tool that helps to guide / direct the student's work (process) and to assess the quality of the products that have been made (result). The rubric as an assessment tool distinguishes the following criteria and percentages: process $(10 \%)$, functioning $(10 \%)$, graphic interface $(10$ $\%)$, creativity $(10 \%)$, programming (20\%), Computational thinking $(15 \%)$, Publication $(5 \%)$ and content of the area $(20 \%)$.

\section{METHODS}

The project methodology is based on the case study. It is proposed as the way to get to the problem, considering the most appropriate method to understand existing discourses in a unique context [10] (Yin, 2003). The case study is developed with a class of 25 students (1st Year) in a high school from Jaén (Spain) and a Natural Science teacher. It is the first time they access a similar experience applying the Scratch language to the curriculum of the subject. The teacher has no previous experience in this area of technology integration in the classroom. The sessions take place in the classroom because it is an ICT center with computers in every classroom. The purpose of using the Scratch language is creating a program and sharing it with the online community. Thus, if the student is capable of creating a suitable program in those twelve sessions, we can see that the overall goal mentioned is fulfilled. Taking into account the students' work, a set of criteria listed in the rubric was proposed in order to ensure that the result is right.
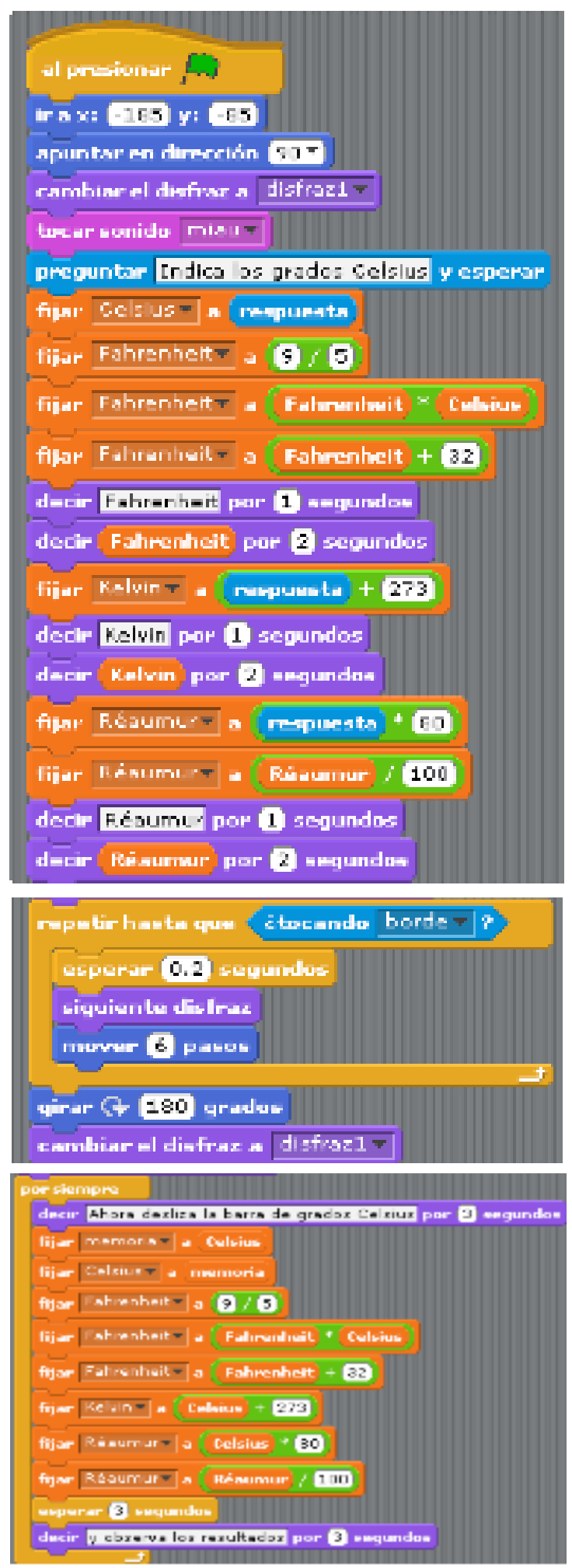

Figure 2. Project blocks

The corpus data were some notes, the researcher's journal, the rubric and a satisfaction survey of students and teachers, designed ad hoc.

The rubric has been used and created by Eduteka and it has been validated in multiple investigations concerning the use of the Scratch language classroom contexts by researchers around the world who have been working with this computer language. 


\section{RESULTS}

From direct observation of the students, it was noticed, analyzed and considered that the group improved to good effect in attitude, aptitude, behavior, teamwork, problem solving, effort to succeed, carrying out of tasks, resolution of complex activities, application of the logical mathematical thinking in the projects developed in Scratch and motivation for the development of the formative process in the competences worked on.

With regard to the learning received, the possibility to work in class with Scratch has been different. The students expressed that the learning of the subject was funny, unlike the teaching staff, who were surprised by the results achieved, the atmosphere in the classroom and the teamwork:

Student 1: It's difficult to understand at first, but then it was very funny.

Student 2: The best thing was to see if it worked.

The possibilities that Scratch offers in order to carry out projects with different levels have allowed each student to develop their creative potential, encouraging them to make progress at their own pace.

Teacher 1: In some cases, they have helped each other promptly.

Teacher 2: If they miss a lesson, they get lost and that is frequent, so it is difficult to follow the pace, they did not use to be absent.

The results (Table I) of the adapted rubric provide us with important data of the work of the students in their Scratch Project, which complement the results in connection with the dimensions analyzed and the percentages given to each of them.

The results of the rubric have been obtained through the statistical program R (version 3.0.0) for the data analysis. The average grade obtained from the group of students is 3.15 in a scale of 1 to 5 ; for that purpose we have taken into account the weighting of each dimension of the rubric. The variance reached is 0.21 and the standard deviation is 0.46. A considerable dispersion of the standard deviation is observed when a wide repertoire of answers is found and it is far from homogeneity, as can be noticed in the dimensions. Programming $[\mathrm{PRG}](0.27)$ and Process [PRO] (1.95).

The statistical descriptors of the dimensions of the rubric that have obtained the highest scores are creativity (4.04), computational thinking (4.04) and content of the area (4.16). The lowest average grade is represented in the dimension of process (2.6) in a scale of 1 to 5 .

The correlation between the eight dimensions of the rubric has been studied through the correlation coefficient of Pearson, and they act as variables. The results obtained show that there is a correspondence between the variables of programming and creativity (0.688). Moreover, there is a strong linear correlation between process and publication, obtaining a correlation of 0.984 , as well as between the latter and the graphic interface with a score of 0.800 . The correspondence between content of the area and graphic interface stands out (0.856), and also does the one between content of the area and programming (0.559). Other variables related to the publication of the end product and the content of the area are worth highlighting $(0.386)$, which shows a low value in relation to the final papers that are published online.

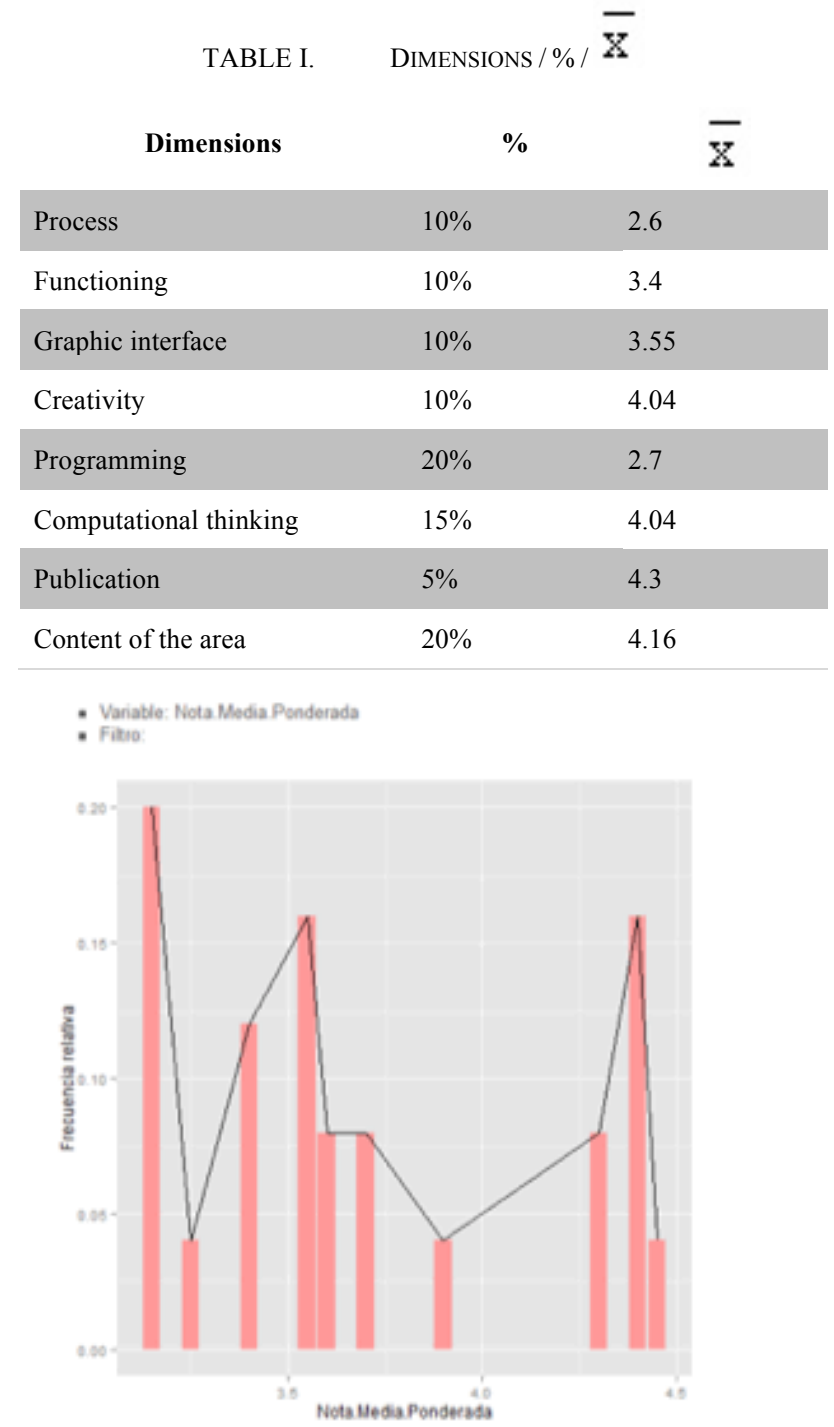

Figure 3. Weighted average grade

In our case, the weighted average grade of each student has been turned into a categorical or one-factor variable, as can be seen in the bar chart enclosed in figure 3 .

\section{CONCLUSIONS}

It has been observed that the Scratch language can support changes for pupils who continuously work with this language. It increases students' motivation in their everyday work, as has been checked in the satisfaction questionnaire. The experience of working with Scratch has been playful and fun.

It has been observed that the Scratch language can support changes for pupils who continuously work with this language. It increases students' motivation in their everyday work, as has been checked in the satisfaction questionnaire. The experience of working with Scratch has been playful and fun.

We could also note that the material is suitable to work in secondary education as different authors and studies say. Despite the short time of implementation of the project itself, positive changes were observed in students regarding the management of Scratch, being $65 \%$ students who have uploaded their own project, along with $35 \%$ who have not succeeded. Scratch language from the per- 
spective of teachers, has allowed Interdisciplinary work with different areas of the curriculum as Social Sciences, Geography and History - Earth, and natural resources and Mathematics. Scratch research should progress not only in curriculum content, but towards the development of skills, emotions, and/or core competencies, constituting an appropriate means to make education a form of transition from primary school to secondary education through constructivist methodologies in a right age to entrench themselves and compare progress in achieving programming projects. As limitations we have found the lack of maintenance of computer equipment, absenteeism of students and the lack of training of teachers in Scratch.

\section{REFERENCES}

[1] Urrea, C., Badilla, E., Miranda, X. y Barrantes, D., Make to think: ideas, spaces and tools. Actualidades investigativas en educación, 2012, 12(1), 1-21.

[2] Papert, S., The children's machine: rethinking school in the ageof the computer. Nueva York, Basic books, 1993.

[3] Resnick, M., Behavior construction kits. Communications of the ACM, 1993, 36(7), 64-71. http://dx.doi.org/10.1145/159544. 159593

[4] Resnick, M. y Silverman, B., Some reflections on designing construction kits for kids. Proceedings of the 2005 conference on Interaction design and children, 2005, pp. 117-122. Boulder, Colorado: ACM Press. http://dx.doi.org/10.1145/1109540.1109556
[5] Resnick, M., Sowing the seeds for a more creative society. Learning and Leading with Technology, 2007, 35(4), 18.

[6] Bustillo-Bayón et al., Analysis of the training process of a group of prisoners in a Scratch's workshop. RELATEC, 2014, vol 13 (1) 37-49. http://mascvuex.unex.es/revistas/index.php/relatec/article/ view/1279

[7] Resnick, M., Maloney, J., Monroy-Hernández, A., Rusk, N., Eastmond, E., Brennan, K., Millner, A., Rosenbaum, E., Siver, J., Silverman, B., y Kafay, Y., Scratch: Programming for al http://web.media.mit.edu/ mres/papers/Scratch-CACM-final.pdf

[8] López-Escribano, C. \& Sánchez-Montoya, R., Scratch in Special Education: Programming for All. RED, Revista de Educación a Distancia, 2012, N 34 http://www.um.es/ead/red/34/scratch.pdf

[9] López García, J. C. Rubric for assessing Scratch projects, 2013. EDUTEKA http://www.eduteka.org/rubricaScratch.php

[10] Yin, R. K., Case study research: Design and methods (3rd ed.). Thousand Oaks, CA: Sage, 2003.

\section{AUTHORS}

Ana María Ortiz-Colón, Department of Education, Faculty of Education, University of Jaén, Campus Las Lagunillas, s/n, Jaén. (23071, Spain)

José Luis Maroto Romo, Department of Information and Communication Technology for Education, IES Oretania, Linares, Jaén (23700, Spain).

Submitted 27 September 2015. Published as resubmitted by the authors 28 January 016 . 